\title{
Prognostic Value of Cardiopulmonary Exercise Testing in Cardiac Patients With Atrial Fibrillation
}

\author{
Hidekazu Tsuneoka, ${ }^{1,2}$ MD, Akira KoIKe, ${ }^{1} \mathrm{MD}$, Osamu Nagayama, ${ }^{1}$ BS, \\ Koji Sakurada, ${ }^{1}$ MS, Jo Kato, ${ }^{2}$ MD, Akira Sato, ${ }^{2}$ MD, Takeshi Yamashita, ${ }^{1}$ MD, \\ and Kazutaka Aonuma, ${ }^{2} \mathrm{MD}$
}

\begin{abstract}
SUMMARY
Parameters obtained from cardiopulmonary exercise testing (CPX) are recognized for their high prognostic value in predicting future cardiac events in cardiac patients. Our group compared the prognostic value of CPX parameters between patients with sinus rhythm (SR) and patients with atrial fibrillation (AF).

Peak $\mathrm{O} 2$ uptake (VO2), the ratio of the increase in VO2 to the increase in work rate ( $\Delta \mathrm{VO} 2 / \Delta \mathrm{WR})$, and the slope of the increase in ventilation to the increase in $\mathrm{CO} 2$ output (VE-VCO2 slope) were obtained from CPX in $72 \mathrm{AF}$ patients and 478 SR patients. The prognostic values of these indices were compared between the two groups.

Six cardiac deaths and 25 cardiac events were observed in the AF group and 9 cardiac deaths and 96 cardiac events were observed in the SR group, over a prospective follow-up period of 1,192 days. The percentages of cardiac deaths and cardiac events were higher in the AF group than in the SR group. In a multivariate Cox proportional hazards analysis, peak VO2 was identified as a sole significant predictor of cardiac death and cardiac events in SR patients and VEVCO2 slope was identified as a sole significant predictor of cardiac death and cardiac events in AF patients.

Our results suggest that the VE-VCO2 slope is strongly predictive of future cardiac events in patients with AF and that peak VO2 is strongly predictive of future cardiac events in SR patients. (Int Heart J 2012; 53: 102-107)
\end{abstract}

Key words: Exercise testing, Peak VO2, Respiratory gas analysis, VE-VCO2 slope

A trial fibrillation (AF) occurs in both patients with overt cardiac disease and patients without organic cardiac disease. ${ }^{1,2)}$ Previous investigations comparing rate control therapy and rhythm control therapy in AF patients have confirmed that rate control performs equally as well as rhythm control for the prevention of death and future events from cardiovascular causes. ${ }^{3,4)}$ Accordingly, rate control has been adopted as a front-line therapy in the management of $\mathrm{AF}^{5)} \mathrm{AF}$, however, is also more strongly associated with poor mortality and morbidity due to congestive heart failure and stroke, compared to sinus rhythm (SR). The mortality risk gets much worse when $\mathrm{AF}$ develops in patients with heart failure. ${ }^{6}$

Cardiopulmonary exercise testing (CPX) has been established as a useful clinical tool for evaluating the severity of disease and the limitations of activities of daily life in cardiac patients. ${ }^{7)}$ Among the parameters obtained from CPX, the peak $\mathrm{O} 2$ uptake (VO2) is traditionally considered as the gold standard for identifying patients with a poor prognosis and selecting candidates for cardiac transplantation. ${ }^{8)}$ The ratio of the increase in $\mathrm{VO} 2$ to the increase in work rate $(\Delta \mathrm{VO} 2 / \Delta \mathrm{WR})$ and the slope of the increase in ventilation (VE) to the increase in $\mathrm{CO} 2$ output (VCO2) (VE-VCO2 slope) are also useful indices of the severity of heart failure and poor prognosis in cardiac patients. ${ }^{9)} \mathrm{CPX}$, however, has not yet been established to be clinically significant in patients with AF.
Cardiopulmonary function in AF depends on complicated contributory factors such as compromised hemodynamics and an irregular and inordinately high heart rate response. Therefore, the indices with recognized value in predicting poor prognosis in patients with SR may not necessarily be useful in patients with AF. In the present study we sought to establish the prognostic significance of CPX in patients with AF through a comparison with patients with SR.

\section{MeTHODS}

Study patients: We enrolled 550 consecutive patients with cardiac disease who underwent cardiopulmonary exercise testing from February 2001 to August 2003 at the Cardiovascular Institute for the evaluation of exercise capacity and/or the severity of heart failure. The etiology of heart disease was coronary artery disease in $335(60.9 \%)$ patients, valvular disease in 161 (29.3\%), idiopathic dilated cardiomyopathy in 35 (6.4\%), and hypertrophic cardiomyopathy in 19 (3.5\%). Among the 161 patients with valvular disease, the etiology was pure mitral valve disease in 65 , pure aortic valve disease in 54, pure tricuspid valve disease in 3 , combined aortic and mitral valve diseases in 20, combined mitral and tricuspid valve diseases in 15 , and all 3 valve diseases in 4 patients.

From the ${ }^{1}$ Cardiovascular Institute, Tokyo, and ${ }^{2}$ Cardiovascular Division, Institute of Clinical Medicine, Graduate School of Comprehensive Human Science, University of Tsukuba, Ibaraki, Japan.

Address for correspondence: Hidekazu Tsuneoka, MD, Cardiovascular Division, Institute of Clinical Medicine, Graduate School of Comprehensive Human Science, University of Tsukuba, 2-1-1 Amakubo, Tsukuba, Ibaraki, Japan.

Received for publication November 9, 2011

Revised and accepted February 13, 2012. 
Cardiopulmonary exercise testing (CPX): An incremental symptom-limited maximal exercise test was performed using an upright, electromagnetically braked cycle ergometer (Corival 400; Lode; Groningen, Holland). After a 4-minute warm-up at $0 \mathrm{~W}$ or $20 \mathrm{~W}$ at $60 \mathrm{rpm}$, the exercise load was increased incrementally by $1 \mathrm{~W}$ every 6 seconds $(10 \mathrm{~W} /$ minute) in 529 patients and by $1 \mathrm{~W}$ every 3 seconds ( $20 \mathrm{~W} /$ minute) in the remaining 21 patients. The slope of the work rate increase was selected based on the subject's daily activity. ECG was monitored continuously during the test (System ML-6500; Fukuda Densi Co., Ltd., Tokyo). Cuff blood pressure was measured at rest on the cycle ergometer, and then every minute during exercise testing with an automatic indirect manometer (STBP-780; Nippon Colin Co., Ltd., Aichi, Japan).

$\mathrm{VO} 2$, VCO2, and VE were measured throughout the test using an Aeromonitor AE-300S (Minato Medical Science, Osaka, Japan). ${ }^{10,11)}$ Before the parameters from the respiratory gas analysis were calculated, breath-by-breath data were interpolated to give second-by-second values. These second-by-sec- ond values were then calculated as successive 3-second averages, and these averages were translated into a 5-point moving average. Peak VO2 was defined as the average value obtained during the last 15 seconds of incremental exercise. $\Delta \mathrm{VO} 2 /$ $\triangle \mathrm{WR}$ was calculated from the data recorded between $30 \mathrm{sec}-$ onds after the start of incremental exercise to 30 seconds before the end of the exercise by a least squares linear regression. ${ }^{9)}$ The VE-VCO2 slope was calculated from the start of incremental exercise to the respiratory compensation point by a least squares linear regression, as previously described. ${ }^{9}$

Follow-up: After the CPX, all the patients were prospectively followed up at the outpatient clinic of the Cardiovascular Institute. The primary endpoint was defined as cardiac death. Causes of cardiac death were categorized into progressive heart failure, sudden cardiac death, and acute myocardial infarction. Sudden cardiac death was diagnosed according to published criteria. ${ }^{12)}$ The secondary endpoint was defined as a composite of a worsening of heart failure requiring hospitalization, worsening of angina pectoris requiring hospitalization, new acute

Table I. Clinical Characteristics of the Subjects

\begin{tabular}{|c|c|c|c|c|}
\hline Variable & $\begin{array}{l}\text { All patients } \\
(n=550)\end{array}$ & $\begin{array}{c}\text { Patients } \\
\text { with SR } \\
(n=478)\end{array}$ & $\begin{array}{l}\text { Patients } \\
\text { with AF } \\
(n=72)\end{array}$ & $P$ \\
\hline Male & $434(78.9 \%)$ & $387(81.0 \%)$ & $47(62.3 \%)$ & $<0.005$ \\
\hline Age, years & $63.4 \pm 10.5$ & $63.2 \pm 10.8$ & $64.3 \pm 8.2$ & NS \\
\hline BMI, $\mathrm{kg} / \mathrm{m}^{2}$ & $23.2 \pm 3.2$ & $23.3 \pm 3.2$ & $22.4 \pm 3.2$ & $<0.05$ \\
\hline \multicolumn{5}{|l|}{ Etiology } \\
\hline CAD & $335(60.9 \%)$ & $323(67.6 \%)$ & $12(16.7 \%)$ & $<0.001$ \\
\hline VD & $161(29.3 \%)$ & $111(23.2 \%)$ & $50(69.4 \%)$ & $<0.001$ \\
\hline DCM & $35(6.4 \%)$ & $27(5.6 \%)$ & $8(11.1 \%)$ & NS \\
\hline $\mathrm{HCM}$ & $19(3.5 \%)$ & $17(3.6 \%)$ & $2(2.8 \%)$ & NS \\
\hline \multicolumn{5}{|l|}{ Echocardiography } \\
\hline LVDd, mm & $51.1 \pm 8.4$ & $50.7 \pm 8.2$ & $53.9 \pm 9.2$ & $<0.005$ \\
\hline LVDs, mm & $35.2 \pm 10.6$ & $34.5 \pm 10.4$ & $39.2 \pm 11.3$ & $<0.001$ \\
\hline LVEF, \% & $59.2 \pm 15.5$ & $60.0 \pm 15.3$ & $53.8 \pm 15.4$ & $<0.005$ \\
\hline \multicolumn{5}{|l|}{ Parameters from CPX } \\
\hline Peak VO2, mL/minute/kg & $18.3 \pm 5.4$ & $18.8 \pm 5.2$ & $14.8 \pm 4.9$ & $<0.0001$ \\
\hline$\Delta \mathrm{VO} 2 / \Delta \mathrm{WR}, \mathrm{mL} /$ minute $/ \mathrm{W}$ & $9.1 \pm 2.2$ & $9.4 \pm 2.0$ & $7.4 \pm 3.0$ & $<0.0001$ \\
\hline VE-VCO2 slope & $32.6 \pm 8.1$ & $31.8 \pm 6.9$ & $38.0 \pm 12.1$ & $<0.0001$ \\
\hline HR at peak, bpm & $128.5 \pm 23.9$ & $126.5 \pm 20.9$ & $141.9 \pm 35.7$ & $<0.0001$ \\
\hline
\end{tabular}

Data are mean \pm SD or number $(\%)$ of patients, unless otherwise indicated. SR indicates sinus rhythm; $\mathrm{AF}$, atrial fibrillation; $\mathrm{BMI}$, body mass index; $\mathrm{CAD}$, coronary artery disease; $\mathrm{VD}$, valvular disease; DCM, dilated cardiomyopathy; and HCM, hypertrophic cardiomyopathy.

Table II. Comparisons of Cardiovascular Events Between the SR and AF Groups

\begin{tabular}{lcccc}
\hline & $\begin{array}{c}\text { All patients } \\
(n=550)\end{array}$ & $\begin{array}{c}\text { Patients with } \\
\text { SR } \\
(n=478)\end{array}$ & $\begin{array}{c}\text { Patients with } \\
\text { AF } \\
(n=72)\end{array}$ & $P$ \\
\hline Primary endpoint & $15(2.7)$ & $9(1.9)$ & $6(8.3)$ & $<0.01$ \\
$\quad$ Death due to worsening of heart failure & $9(1.6)$ & $5(1.0)$ & $4(5.6)$ & $<0.05$ \\
Sudden cardiac death & $5(1.0)$ & $3(0.6)$ & $2(2.8)$ & $\mathrm{NS}$ \\
$\quad$ Death due to acute myocardial infarction & $1(0.2)$ & $1(0.2)$ & $0(0.0)$ & $\mathrm{NS}$ \\
Secondary endpoint & $121(22.0)$ & $96(20.1)$ & $25(34.7)$ & $<0.01$ \\
Hospitalization due to worsening of heart failure & $64(11.6)$ & $45(9.4)$ & $19(26.4)$ & $<0.001$ \\
Hospitalization due to worsening of angina pectoris & $48(8.7)$ & $47(9.8)$ & $1(1.4)$ & $<0.05$ \\
Acute myocardial infarction & $1(0.2)$ & $1(0.2)$ & $0(0.0)$ & $\mathrm{NS}$ \\
Cardiac death & $8(1.5)$ & $3(0.6)$ & $5(7.0)$ & $<0.005$ \\
\hline
\end{tabular}

Data are number (\%) of patients. SR indicates sinus rhythm and AF, atrial fibrillation. 
myocardial infarction, and cardiac death. Only the first event in each patient was included in this analysis.

Statistics: Data are presented as the mean \pm SD. The prevalence of any underlying disease, the indices obtained from echocardiography, and the indices obtained from CPX were compared between the AF and SR groups using the unpaired $t$ test or Fisher's exact test, where appropriate. Differences in survival between the two groups were detected by the KaplanMeier method and compared using the log-rank test. Univariate and multivariate Cox proportional hazards models were used to measure the impact of the exercise test results on eventfree survival time. For all comparisons, $P<0.05$ was considered statistically significant. All analyses were performed using JMP 9.0.0 (SAS Institute Inc.).

\section{RESUlts}

Among the 550 patients enrolled in the study, 72 patients $(13.0 \%)$ were diagnosed with chronic AF (Table I). The AF group had a lower percentage of males than the SR group. The etiology of heart disease in the AF patients was valvular disease in $69.4 \%$ of the cases, coronary artery disease in $16.7 \%$, dilated cardiomyopathy in $11.1 \%$, and hypertrophic cardiomyopathy in $2.8 \%$. The AF group had a higher prevalence of valvular disease and a lower prevalence of coronary artery disease than the SR group. Among the prescribed medications influencing cardiopulmonary function, $\beta$-blockers were more prev- alent in the AF patients than in the SR patients (19.4 versus $38.7 \%, P<0.005)$.

The AF group had a significantly higher left ventricular end-diastolic diameter (LVDd) $(53.9 \pm 9.2$ versus $50.7 \pm 8.2$ $\mathrm{mm}, P<0.005)$ and left ventricular end-systolic diameter (LVDs) $(39.2 \pm 11.3$ versus $34.5 \pm 10.4 \mathrm{~mm}, P<0.001)$ than the SR group. The AF group had a significantly lower left ven-

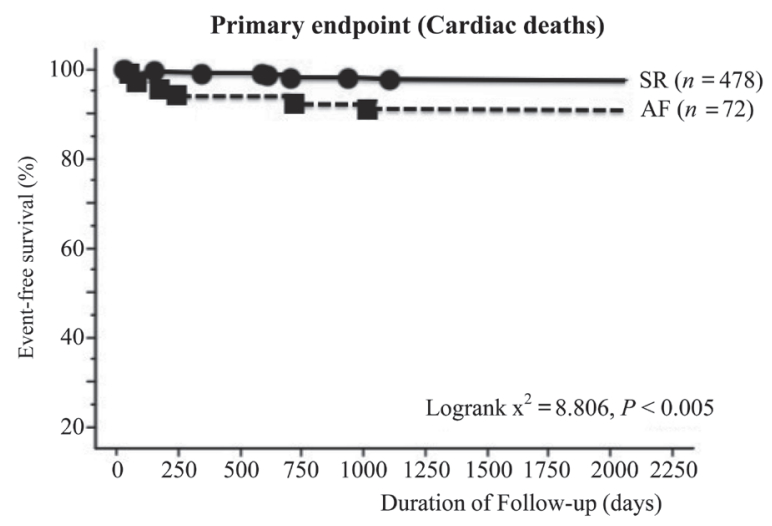

Figure. Kaplan-Meier survival curves in patients stratified into two groups on the basis of the cardiac rhythm: patients with sinus rhythm (SR) and patients with atrial fibrillation (AF). The survival rate in patients with AF was significantly lower than that in patients with SR $(P<0.005)$.

Table III. Predictors of Cardiac Death in Patients With Sinus Rhythm

\begin{tabular}{|c|c|c|c|c|c|c|c|c|}
\hline \multirow{2}{*}{ Variable } & \multicolumn{4}{|c|}{ Univariate Analysis } & \multicolumn{4}{|c|}{ Multivariate Analysis } \\
\hline & $\chi^{2}$ & $P$ & HR & $95 \% \mathrm{CI}$ & $\chi^{2}$ & $P$ & HR & $95 \% \mathrm{CI}$ \\
\hline Age & 0.964 & 0.3262 & 1.035 & $0.966-1.11$ & 0.022 & 0.8825 & 1.006 & $0.933-$ \\
\hline Gender & 0.093 & 0.7604 & 0.783 & $0.163-3.771$ & 0.003 & 0.9575 & 0.950 & $0.146-$ \\
\hline BMI & 2.739 & 0.0981 & 0.831 & $0.668-1.035$ & 1.700 & 0.1922 & 0.829 & $0.629-1.099$ \\
\hline Peak VO2 & 16.269 & $<0.0001$ & 0.728 & $0.625-0.850$ & 5.016 & 0.0251 & 0.648 & $0.443-0.947$ \\
\hline$\Delta \mathrm{VO} 2 / \Delta \mathrm{WR}$ & 18.864 & $<0.0001$ & 0.611 & $0.489-0.763$ & 0.039 & 0.8436 & 1.057 & $0.610-1.830$ \\
\hline VE-VCO2 slope & 15.097 & 0.0001 & 1.097 & $1.047-1.14$ & 0.087 & 0.7683 & 1.014 & $0.924-1.112$ \\
\hline Peak HR & 3.681 & 0.0550 & 0.970 & $0.940-1.001$ & 0.125 & 0.7237 & 0.991 & $0.940-1.044$ \\
\hline LVDd & 24.743 & $<0.0001$ & 1.129 & $1.076-1.184$ & 1.405 & 0.2359 & 0.876 & $0.705-1.090$ \\
\hline LVDs & 29.859 & $<0.0001$ & 1.115 & $1.072-1.159$ & 6.035 & 0.0140 & 1.352 & $1.063-1.720$ \\
\hline LVE & 19.937 & $<0.0001$ & 0.908 & $0.870-0.947$ & 2.216 & 0.1366 & 1.086 & $0.974-1.212$ \\
\hline
\end{tabular}

HR indicates hazard ratio and CI, confidence interval.

Table IV. Predictors of Cardiac Events in Patients With Sinus Rhythm

\begin{tabular}{|c|c|c|c|c|c|c|c|c|}
\hline \multirow{2}{*}{ Variable } & \multicolumn{4}{|c|}{ Univariate Analysis } & \multicolumn{4}{|c|}{ Multivariate Analysis } \\
\hline & $\chi^{2}$ & $P$ & HR & $95 \% \mathrm{CI}$ & $\chi^{2}$ & $P$ & HR & $95 \% \mathrm{CI}$ \\
\hline Age & 5.482 & 0.0192 & 1.025 & $1.004-1.046$ & 3.040 & 0.0812 & 1.019 & $0.998-1.041$ \\
\hline Gender & 0.610 & 0.4350 & 1.246 & $0.718-2.162$ & 3.813 & 0.0508 & 1.953 & $0.997-3.825$ \\
\hline BMI & 1.281 & 0.2577 & 0.962 & $0.899-1.029$ & 2.973 & 0.0847 & 0.936 & $0.868-1.009$ \\
\hline Peak VO2 & 33.922 & $<0.0001$ & 0.878 & $0.840-0.917$ & 10.419 & 0.0012 & 0.884 & $0.821-0.953$ \\
\hline$\Delta \mathrm{VO} 2 / \Delta \mathrm{WR}$ & .983 & $<0.0001$ & 0.789 & $0.722-0.863$ & 1.859 & 0.1728 & 0.896 & $0.765-1.049$ \\
\hline VE-VCO2 slope & 16.175 & $<0.0001$ & 1.046 & $1.023-1$. & 0.329 & 0.5662 & 0.991 & $0.961-1.022$ \\
\hline Peak HR & 10.213 & 0.0014 & 0.985 & $0.975-0.994$ & 0.506 & 0.4767 & 1.005 & $0.992-1.017$ \\
\hline LVDd & 17.273 & $<0.0001$ & 1.050 & $1.026-1.074$ & 0.896 & 0.3438 & 1.057 & $0.942-1.186$ \\
\hline LVDs & 20.839 & $<0.0001$ & 1.041 & $1.023-1.060$ & 0.029 & 0.8637 & 1.013 & $0.872-1.178$ \\
\hline LVEF & 16.701 & $<0.0001$ & 0.975 & $0.963-0.987$ & 0.259 & 0.6111 & 1.015 & $0.960-1.072$ \\
\hline
\end{tabular}

HR indicates hazard ratio and CI, confidence interval. 
Table V. Predictors of Cardiac Death in Patients With Atrial Fibrillation

\begin{tabular}{|c|c|c|c|c|c|c|c|c|}
\hline \multirow{2}{*}{ Variable } & \multicolumn{4}{|c|}{ Univariate Analysis } & \multicolumn{4}{|c|}{ Multivariate Analysis } \\
\hline & $\chi^{2}$ & $P$ & HR & $95 \% \mathrm{CI}$ & $\chi^{2}$ & $P$ & HR & $95 \% \mathrm{CI}$ \\
\hline Age & 0.001 & 0.9698 & 1.002 & $0.910-1.103$ & 0.172 & 0.6781 & 1.049 & $0.838-1.312$ \\
\hline Gender & 0.824 & 0.3639 & 2.705 & $0.316-23.179$ & 0.316 & 0.5740 & 2.748 & $0.081-93.225$ \\
\hline BMI & 0.531 & 0.4661 & 0.910 & $0.706-1.173$ & 1.772 & 0.1832 & 1.709 & $0.776-3.761$ \\
\hline Peak VO2 & 4.955 & 0.0260 & 0.757 & $0.593-0.967$ & 0.486 & 0.4858 & 1.251 & $0.667-2.345$ \\
\hline$\Delta \mathrm{VO} 2 / \Delta \mathrm{WR}$ & 4.946 & 0.0261 & 0.763 & $0.600-0.968$ & 0.020 & 0.8874 & 0.937 & $0.378-2.320$ \\
\hline VE-VCO2 slope & 8.586 & 0.0034 & 1.090 & $1.029-1.154$ & 3.907 & 0.0481 & 1.293 & $1.002-1.668$ \\
\hline Peak HR & 4.061 & 0.0439 & 0.970 & $0.942-0.999$ & 3.304 & 0.0691 & 0.947 & 0.894-1.004 \\
\hline LVDd & 0.651 & 0.4196 & 1.033 & $0.955-1.116$ & 1.083 & 0.2980 & 0.461 & $0.107-1.984$ \\
\hline LVDs & 2.174 & 0.1403 & 1.044 & $0.986-1.106$ & 1.086 & 0.2973 & 2.557 & $0.437-14.954$ \\
\hline LVEF & 4.180 & 0.0409 & 0.954 & $0.912-0.998$ & 0.695 & 0.4045 & 1.261 & $0.731-2.175$ \\
\hline
\end{tabular}

HR indicates hazard ratio and CI, confidence interval.

Table VI. Predictors of Cardiac Events in Patients With Atrial Fbrillation

\begin{tabular}{|c|c|c|c|c|c|c|c|c|}
\hline \multirow{2}{*}{ Variable } & \multicolumn{4}{|c|}{ Univariate Analysis } & \multicolumn{4}{|c|}{ Multivariate Analysis } \\
\hline & $\chi^{2}$ & $P$ & $\mathrm{HR}$ & $95 \% \mathrm{CI}$ & $\chi^{2}$ & $P$ & $\mathrm{HR}$ & $95 \% \mathrm{CI}$ \\
\hline Age & 2.978 & 0.0844 & 0.958 & $0.913-1.006$ & 1.050 & 0.3056 & 0.969 & $0.913-1.029$ \\
\hline Gender & 0.032 & 0.8586 & 1.084 & $0.448-2.619$ & 0.096 & 0.7569 & 1.212 & $0.359-4.093$ \\
\hline BMI & 3.008 & 0.0828 & 0.887 & $0.774-1.016$ & 0.069 & 0.7931 & 0.975 & $0.807-1.178$ \\
\hline Peak VO2 & 3.318 & 0.0685 & 0.921 & $0.843-1.006$ & 0.384 & 0.5353 & 0.936 & $0.761-1.152$ \\
\hline$\Delta \mathrm{VO} 2 / \Delta \mathrm{WR}$ & 2.201 & 0.1379 & 0.901 & $0.786-1.034$ & 0.157 & 0.6915 & 1.067 & $0.775-1.469$ \\
\hline VE-VCO2 slope & 11.478 & 0.0007 & 1.049 & $1.021-1.079$ & 4.501 & 0.0339 & 1.050 & 1.004-1.099 \\
\hline Peak HR & 0.113 & 0.7369 & 0.998 & 0.987-1.009 & 0.624 & 0.4295 & 1.006 & $0.991-1.022$ \\
\hline LVDd & 7.362 & 0.0067 & 1.058 & $1.016-1.102$ & 0.108 & 0.7425 & 0.915 & $0.539-1.554$ \\
\hline LVDs & 6.008 & 0.0142 & 1.044 & $1.009-1.081$ & 0.402 & 0.5261 & 1.264 & $0.613-2.608$ \\
\hline LVEF & 3.089 & 0.0788 & 0.978 & $0.953-1.003$ & 0.623 & 0.4301 & 1.113 & $0.853-1.451$ \\
\hline
\end{tabular}

HR indicates hazard ratio and CI, confidence interval.

tricular ejection fraction (LVEF) than the SR group $(53.8 \pm$ 15.4 versus $60.0 \pm 15.3 \%, P<0.005)$. The $\mathrm{AF}$ group had a lower peak VO2 $(14.8 \pm 4.9$ versus $18.8 \pm 5.2 \mathrm{~mL} / \mathrm{min} / \mathrm{kg}, P<$ $0.0001)$, lower $\Delta \mathrm{VO} 2 / \Delta \mathrm{WR}(7.4 \pm 3.0$ versus $9.4 \pm 2.0 \mathrm{~mL} /$ minute/W, $P<0.0001)$, and higher VE-VCO2 slope $(38.0 \pm$ 12.1 versus $31.8 \pm 6.9, P<0.0001)$ than the $\mathrm{SR}$ group. The $\mathrm{AF}$ group also had a higher heart rate at peak exercise (141.9 \pm 35.7 versus $126.5 \pm 20.9 \mathrm{bpm}, P<0.0001$ ).

Fifteen cardiac deaths occurred over the follow-up period of 1,192 \pm 546 days (Table II), but none of the patients died of cerebrovascular causes. Of the cardiac deaths, 9 (4 in the AF group and 5 in the SR group) were deaths due to progressive heart failure, 5 ( 2 in the AF group and 3 in the SR group) were sudden cardiac deaths, and 1 (in the SR group) was death due to acute myocardial infarction. The Figure shows the KaplanMeier survival between the SR and AF groups. The KaplanMeier survival curves demonstrated a significantly lower survival rate in the $\mathrm{AF}$ group than in the SR group $(P<0.005)$. The secondary endpoint, a composite of a worsening of heart failure requiring hospitalization, worsening of angina pectoris requiring hospitalization, new acute myocardial infarction, and cardiac death, occurred in $25 \mathrm{AF}$ patients (34.7\%) and $96 \mathrm{SR}$ patients $(20.1 \%)$. In addition to death due to a worsening of heart failure, hospitalization due to a worsening of heart failure was also significantly higher in the AF group than in the SR group $(P<0.001)$.

Table III shows the univariate and multivariate Cox proportional hazards analyses of the associations between cardi- opulmonary indices and cardiac deaths in patients with SR. In the univariate analysis, peak $\mathrm{VO} 2, \Delta \mathrm{VO} 2 / \Delta \mathrm{WR}, \mathrm{VE}-\mathrm{VCO} 2$ slope, LVDd, LVDs, and LVEF were all found to be significant indices for survival. In the multivariate analysis encompassing these indices, peak VO2 and LVDs were the only independent predictors of cardiac death. Table IV shows a Cox proportional hazards analysis of the association between the cardiopulmonary indices and cardiac events (secondary endpoint) in patients with SR. In the multivariate analysis, peak VO2 was the only independent predictor of cardiac events.

Table V shows the univariate and multivariate Cox proportional hazards analyses of the associations between cardiopulmonary indexes and cardiac deaths in patients with AF. In the multivariate analysis, the VE-VCO2 slope was the only independent predictor of cardiac death. Similarly, the VE-VCO2 slope was the only independent predictor of cardiac events (secondary endpoint) in the multivariate analysis (Table VI).

Since the etiology of cardiac disease differed significantly between SR patients and AF patients, we compared cardiopulmonary indices between SR patients with coronary artery disease $(n=323)$ and those with valvular disease $(n=111)$. It was found that the former had significantly lower values of LVEF, peak VO2, and heart rate at peak exercise, and a higher value of VE-VCO2 slope than the latter. Between these 2 groups, however, there were no significant differences in the event rates for the primary and secondary endpoints, although patients with coronary artery disease had a higher rate of hospitalization due to a worsening of angina pectoris and those 
with valvular disease had a higher rate of hospitalization due to a worsening of heart failure.

\section{Discussion}

CPX yields a wealth of information beyond what is normally available from standard exercise testing for the management of complex cardiovascular and pulmonary disease. ${ }^{13)} \mathrm{A}$ strong relationship between peak VO2 and peak exercise cardiac output has been found in patients with heart failure. ${ }^{14,15)}$ $\Delta \mathrm{VO} 2 / \Delta \mathrm{WR}$ reflects the rate of increase in cardiac output during incremental exercise. $\Delta \mathrm{VO} 2 / \Delta \mathrm{WR}$ in healthy subjects is approximately $10 \mathrm{~mL} / \mathrm{minute} / \mathrm{W}$, while that in heart disease patients falls to progressively lower levels as the disease worsens. ${ }^{16,17)}$ Decreased peak VO2 and $\Delta \mathrm{VO} 2 / \Delta \mathrm{WR}$ are usually seen in patients with coronary artery disease, depending on its severity, dilated cardiomyopathy, valvular disease, and any other cardiac disease with exercise-induced left ventricular dysfunction. The VE-VCO2 slope ranges from approximately 24 to 34 in healthy subjects. ${ }^{18,19)}$ Theoretically, a steep VE$\mathrm{VCO} 2$ slope during exercise is assumed to relate mainly to a ventilation-perfusion mismatch, such as an increased ratio of pulmonary dead space to tidal volume. A steep VE-VCO2 slope implies the presence of heart failure resulting from either systolic or diastolic dysfunction, regardless of the etiology of cardiac disease. Concomitant lung diseases may also steepen this slope.

Indices obtained from CPX have been shown to predict the prognosis in cardiac patients in many studies. ${ }^{13)}$ In 1991, Mancini, et $a l^{8)}$ proposed that cardiac transplantation can be safely deferred in ambulatory patients with severe left ventricular dysfunction when the peak VO2 is more than $14 \mathrm{~mL} /$ minute/kg. Since then, the peak VO2 has been considered a key index to consider when contemplating cardiac transplantation. In 1997, Chua, et $a l^{19)}$ found that cardiac patients with a higher VE-VCO2 slope had a poorer prognosis. In 2002, it was also reported that a shallow slope of $\Delta \mathrm{VO} 2 / \Delta \mathrm{WR}$ was associated with an increased risk of death in cardiac patients. ${ }^{9)}$ However, the best predictor of poor prognosis among the several CPX indices is still open to controversy. Our findings from the present study identify VE-VCO2 slope as a strong predictor of future cardiac events in patients with $\mathrm{AF}$ and identify peak $\mathrm{VO} 2$ as a strong predictor of future cardiac events in SR patients.

Functional factors such as contractile function, reservoir function, and conduit function govern the workings of the left atrium. ${ }^{20-22)}$ Theoretically, AF causes a functional loss of the left atrium, especially the loss of contractile function. An observation from De Ferrari, et $a l^{23)}$, namely, that AF leads to a more severe disease rating in the New York Heart Association classification, indicates that AF aggravates heart failure. As compared to the other CPX indices, VE-VCO2 slope was the better predictor of both cardiac death (primary endpoint) and cardiac events (secondary endpoint) in the AF patients of the present study. A worsening of heart failure was the main cause of death and cardiac events in these patients. The percentage of death due to a worsening of heart failure and the percentage of hospitalization due to a worsening of heart failure were both higher in AF patients than in SR patients. We can therefore argue that the VE-VCO2 slope was the best CPX parameter for predicting higher mortality and morbidity resulting from a worsening of heart failure in AF patients. VE-VCO2 slope might be a better prognostic indicator than peak $\mathrm{VO} 2$ in patients who face a high risk of a worsening of heart failure.

In 2000, Jaiis, et $a l^{24)}$ found that the left ventricular end-diastolic pressure was higher in lone AF patients than in control subjects, suggesting the presence of left ventricular diastolic dysfunction in patients with lone AF. It has been demonstrated by Guazzi, et $a l^{25)}$ that the prognostic power of $\mathrm{VE}-\mathrm{VCO} 2$ slope was superior to that of peak VO2 in patients with diastolic heart failure, in spite of a similar prognostic power of these indices in patients with systolic heart failure. An abnormal VEVCO2 response has also been correlated with elevated pulmonary pressures. ${ }^{13)}$ Thus, diastolic dysfunction arising from AF itself or from the underlying cardiac disease in AF patients must, at least in part, be associated with the prognostic superiority of VE-VCO2 slope in AF patients.

Study limitations: The AF group in the present study had not only a lower peak VO2 and lower $\Delta \mathrm{VO} 2 / \Delta \mathrm{WR}$, but also a higher VE-VCO2 slope, compared with the SR group. The AF group had a significantly lower survival rate than the SR group. For this study we enrolled consecutive cardiac patients who underwent CPX for evaluation of exercise capacity and/or the severity of heart failure. For this reason, the background characteristics differed considerably between the AF and SR groups. In comparing the groups, the AF had a lower percentage of males, a higher prevalence of valvular disease, and a lower prevalence of coronary artery disease. The AF group had a significantly lower LVEF than the SR group. As such, the greater impairment of cardiopulmonary function during exercise in the AF patients might have been due not to the AF itself, but to other factors related to cardiopulmonary function during exercise. Since the prevalence of valvular disease is high in AF patients and that of coronary artery disease is high in SR patients in the present study, there is a possibility that a strong predictor of future cardiac events is the VE-VCO2 slope in patients with valvular disease and peak VO2 in patients with coronary artery disease irrespective of cardiac rhythm. However, we could not perform a Cox proportional hazards analysis in a subgroup to clarify this issue, due to the small number of subjects.

Conclusions: The findings from the present study suggest that VE-VCO2 slope is strongly predictive of future cardiac events in patients with $\mathrm{AF}$ and that peak $\mathrm{VO} 2$ is strongly predictive of future cardiac events in SR patients. The VE-VCO2 slope might be a better indicator than peak $\mathrm{VO} 2$ in predicting a worsening of heart failure in cardiac patients.

\section{REFERENCES}

1. Kannel WB, Abbott RD, Savage DD, McNamara PM. Epidemiologic features of chronic atrial fibrillation: the Framingham Study. N Engl J Med 1982; 306: 1018-22.

2. Kannel WB, Wolf PA, Benjamin EJ, Levy D. Prevalence, incidence, prognosis, and predisposing conditions for atrial fibrillation: population-based estimates. Am J Cardiol 1998; 82: 2N-9N.

3. Wyse DG, Waldo AL, DiMarco JP, et al. A comparison of rate control and rhythm control in patients with atrial fibrillation. $\mathrm{N}$ Engl J Med 2002; 347: 1825-33.

4. Van Gelder IC, Hagens VE, Bosker HA, et al. A comparison of rate control and rhythm control in patients with recurrent persist- 
ent atrial fibrillation. N Engl J Med 2002; 347: 1834-40.

5. Van Gelder IC, Groenveld HF, Crijns HJ, et al. Lenient versus strict rate control in patients with atrial fibrillation. N Engl J Med 2010; 362: 1363-73.

6. Chamberlain AM, Redfield MM, Alonso A, Weston SA, Roger VL. Atrial fibrillation and mortality in heart failure: a community study. Circ Heart Fail 2011; 4: 740-6.

7. Wasserman K. New concepts in assessing cardiovascular function. Circulation 1988; 78: 1060-71.

8. Mancini DM, Eisen H, Kussmaul W, Mull R, Edmunds LH Jr, Wilson JR. Value of peak exercise oxygen consumption for optimal timing of cardiac transplantation in ambulatory patients with heart failure. Circulation 1991; 83: 778-86.

9. Koike A, Itoh H, Kano M, et al. Prognostic power of ventilatory responses during submaximal exercise in patients with chronic heart disease. Chest 2002; 121: 1581-8.

10. Koike A, Hiroe M, Adachi $\mathrm{H}$, et al. Oxygen uptake kinetics are determined by cardiac function at onset of exercise rather than peak exercise in patients with prior myocardial infarction. Circulation 1994; 90: 2324-32.

11. Koike A, Nagayama O, Goda A, et al. Does the severity of central sleep apnea correlate with respiratory gas indexes during cardiopulmonary exercise testing? Int Heart J 2006; 47: 889-900.

12. Torp-Pedersen C, Køber L, Elming H, Burchart H. Classification of sudden and arrhythmic death. Pacing Clin Electrophysiol 1997; 20: 2545-52.

13. Balady GJ, Arena R, Sietsema K, et al. Clinician's guide to cardiopulmonary exercise testing in adults: a scientific statement from the American Heart Association. Circulation 2010; 122: 191-225. (Review)

14. Franciosa JA, Baker B, Seth L. Pulmonary versus systemic hemodynamics in determining exercise capacity of patients with chronic left ventricular failure. Am Heart J 1985; 110: 807-13.

15. Volterrani M, Clark AL, Ludman PF, et al. Predictors of exercise capacity in chronic heart failure. Eur Heart J 1994; 15: 801-9.

16. Hansen JE, Sue DY, Oren A, Wasserman K. Relation of oxygen uptake to work rate in normal men and men with circulatory disorders. Am J Cardiol 1987; 59: 669-74.

17. Itoh H, Taniguchi K, Koike A, Doi M. Evaluation of severity of heart failure using ventilatory gas analysis. Circulation 1990; 81: II31-7.

18. Metra M, Dei Cas L, Panina G, Visioli O. Exercise hyperventilation in chronic congestive heart failure, and its relation to functional capacity and hemodynamics. Am J Cardiol 1992; 70: 622-8.

19. Chua TP, Ponikowski P, Harrington D, et al. Clinical correlates and prognostic significance of the ventilatory response to exercise in chronic heart failure. J Am Coll Cardiol 1997; 29: 1585-90.

20. Grant C, Bunnell IL, Greene DG. The reservoir function of the left atrium during ventricular systole. An angiographic study of atrial stroke volume and work. Am J Med 1964; 37: 36-43.

21. Toma Y, Matsuda Y, Moritani K, et al. Left atrial conduit function for left ventricular filling dynamics in patient with myocardial infarction. Cathet Cardiovasc Diagn 1989; 18: 85-9.

22. Matsuzaki M, Tamitani M, Toma Y, et al. Mechanism of augmented left atrial pump function in myocardial infarction and essential hypertension evaluated by left atrial pressure-dimension relation. J Am Coll Cardiol 1991; 67: 1121-6.

23. De Ferrari GM, Klersy C, Ferrero P, et al. Atrial fibrillation in heart failure patients: prevalence in daily practice and effect on the severity of symptoms. Data from the ALPHA study registry. Eur J Heart Fail 2007; 9: 502-9.

24. Jaïs P, Peng JT, Shah DC, et al. Left ventricular diastolic dysfunction in patients with so-called lone atrial fibrillation. J Cardiovasc Electrophysiol 2000; 11: 623-5.

25. Guazzi M, Myers J, Arena R. Cardiopulmonary exercise testing in the clinical and prognostic assessment of diastolic heart failure. J Am Coll Cardiol 2005; 46: 1883-90. 